\title{
LA CEGUERA CIVIL DE POLIFEMO Y LA "EDAD DE LAS PRETENSIONES". ANOTACIONES JUSFILOSÓFICAS SOBRE DERECHOS, DEBERES Y RELACIÓN SOCIAL ${ }^{1}$.
}

\section{THE CIVIL POLIFEME BLINDNESS AND THE "AGE OF PRETENSIONS". JUSPHILOSOPHICAL NOTES ON RIGHTS, DUTIES AND SOCIAL RELATIONSHIP.}

\author{
Christian CROCETTA
}

Resumen. En los orígenes de esta reflexión está la atención a un derecho que no mira a un sujeto, individual en abstracto, sino a la persona, en la dimensión concreta de su vida cotidiana. Un derecho más "humanizado", que sepa detenerse en el presente, en la que alguein sintetiza como "edad de las pretensiones", sabiendo comprender sus límites y sintiendo la necesidad de rigenerarla, a través de un énfasis más marcado en dos términos relacionados, derechos y deberes, es decir recuperar la dimensión de la relación social que se expresa en los deberes y sin los cuales los derechos se traducen en vacías pretenciones subjetivas sin confirmación. Necesitamos, por lo tanto, volver al deber, no para reafirmar legalidad y seguridad, sino para resaltar claramente el vínculo esencial entre los derechos y deberes, que pueden reafirmarse juntos, como derechos y deberes fundamentales del hombre. Para poner en evidencia la necesidad de que la coexistencia -deber fundamental, imprescindible e ineludible- sea una coexistencia solidaria, para un bien no "inmune" sino "común", para un "vínculo entre hombres», un vínculo social que convierta el individuo en persona entre otras personas.

Abstract. At the origins of this reflection is the attention to a right that does not look at a subject, individual in the abstract, but at the person, in the concrete dimension of their daily lives. A more "humanized" right, which knows how to stop in the present, in which someone synthesizes as "age of pretensions", knowing how to understand its limits and feeling the need to govern it, through a more marked emphasis on two related terms, rights and duties, that is to recover the dimension of the social relationship that is expressed in the duties and without which the rights are translated into empty subjective pretensions without confirmation. We need, therefore, to return to duty, not to reaffirm legality and security, but to clearly highlight the essential link between rights and duties, which can be reaffirmed together, as fundamental rights and duties of man. To highlight

\footnotetext{
${ }^{1}$ Traducido por Carlo Mercurelli.
} 
the need for coexistence - a fundamental, essential and unavoidable duty - to be a coexistence of solidarity, for a good that is not "immune" but "common", for a "bond between men", a social bond that the individual converts in person among other people.

Palabras clave: derechos, deberes, responsabilidades, relaciones sociales

Keywords. rights, obligations, responsibilities, social relations

\section{UN DERECHO ATENTO A LA FRAGILIDAD}

En los orígenes de esta reflexión está la atención a un derecho que no mira a un sujeto, individual en abstracto, sino a la persona, en la dimensión concreta de su vida cotidiana. Un derecho más "humanizado", que sepa detenerse en el presente, en la que alguein sintetiza como "edad de las pretensiones" , y que talvez podríamos llamar, de manera alternativa, "segunda época" del "tiempo de los derechos", sabiendo comprender sus límites y sintiendo la necesidad de rigenerarla, a través de un énfasis más marcado en dos términos relacionados, derechos y deberes, es decir recuperar la dimensión de la relación social que se expresa en los deberes y sin los cuales los derechos se traducen en vacías pretenciones subjetivas sin confirmación, porque, como argumentó Simone Weil, «el derecho es eficaz si viene reconocido» y «un derecho que nadie reconoce, no vale mucho» ${ }^{4}$.

No se trata, por lo tanto, de «"hablar mal" de los derechos», sino de «reafirmar la conexión que los derechos tienen con la existencia de los deberes» y decir «"primero el deber, y después los derechos" ${ }^{5}$, para confirmar que «la cara del otro me interpela incluso antes de que me dé cuenta, suscita en mí el sentimiento de que le sea reconocido un bien, un valor, un requisito que estriba en él» ${ }^{6}$.

\footnotetext{
${ }^{2}$ ZATTI P., "Parole fra noi così diverse». Per un'ecologia del rapporto terapeutico", in Nuova Giur. Civ. Comm., 3, 2012, p. 150.

${ }^{3}$ POSSENTI V., Diritti umani. L'età delle pretese, Soveria Mannelli (CZ), Rubbettino, 2017.

${ }^{4}$ WEIL, S., La prima radice. Preludio a una dichiarazione dei doveri dell'uomo, Milano, Edizioni di Comunità, 2017, p. 9.

${ }^{5}$ GRECO, T., Prima il dovere. Una critica della filosofia dei diritti, in S. Mattarelli (a cura di), Il senso della Repubblica. Doveri, Milano, Franco Angeli, 2007, pp. 15-16.

${ }^{6}$ POSSENTI, V., Diritti umani. L'età delle pretese, cit., p. 96.
} 
Por lo tanto no es una apología del deber ${ }^{7}$, la que se quiere realizar en este escrito -con un deslizamiento, incluso involontario, y una degeneración hacia una forma de autoritarismo- sino la intención de subrayar que, en un contexto en el que el otro viene expulsado, existe el riesgo de perder la dimensión de la responsabilidad ${ }^{8}$; solo hay preferencias subjetivas y atomistas y un plegamiento individualista destructivo de la socialidad, que en cambio es una presuposición esencial del derecho junta con la humanidad para la cual viene constituido ${ }^{9}$.

Hoy es necesario un derecho que razone sobre la condición de vulnerabilidad ${ }^{10}$, a partir de la aceptación de la categoría de fragilidad como una connotación constitutiva de la condicióm criatural humana y no como un evento o característica de la cual se debe escapar. Sin embargo en un presente que habla el lenguaje efímero, como recuerda Luigi Alici, «la fragilidad deja de ser [...] la cifra de una condición ontológica, para convertirse en una sombra del deseo, un epifenómeno transitorio, que el mercado de las biotecnologías promete reducir progresivamente en términos mínimos» ${ }^{11}$. No es una «condición estructural de la existencia», no es el código constitutivo de la existencia humana sino «una forma coyuntural de vivir [que] como tal, representa un límite extrínseco y mortificante, que se connota por términos axiológicamente negativos» ${ }^{12}$.

\footnotetext{
${ }^{7}$ Cpd. GUASTINI, R., "Dovere giuridico", in Enc. Giur., 1990, XXI, 4; Id., "Obbligo", in Enc. Giur., 1990, XXI; PECES BARBA MARTINEZ, G., "Diritti e doveri fondamentali", in Dig. Disc. pubbl., 1990, V, 139; TARLI BARBIERI, G., "Doveri inderogabili", in Dizionario di diritto pubblico, III, Milano, 2006, pp. 2066 ss.

${ }^{8}$ Respecto a la semántica de la responsabilidad, cpd. FODDAI, M.A., Sulle tracce della responsabilità. Idee e norme dell'agire responsabile, Torino, Giappichelli, 2005, pp. 1-33; VERGANI, M., Responsabilità. Rispondere di sé, rispondere all'altro, Milano, Raffaello Cortina, 2015.

${ }^{9}$ Cpd. GROSSI, P., Prima lezione di diritto, Roma-Bari, Laterza, 2007, p. 13.

${ }^{10}$ Cpd. ZANETTI, G., Filosofia della vulnerabilità, Carocci, Roma, 2019; GIOLO, O; PASTORE, B., Vulnerabilità. Analisi multidisciplinare di un concetto, Roma, Carocci, 2018; BERNARDINI, M.G., "Il soggetto vulnerabile. Status e prospettive di una categoria (giuridicamente) controversa", in Rivista di filosofia del diritto, Journal of Legal Philosophy, 2017, 2, pp. 365-384; CHENAL, R., "La definizione della nozione di vulnerabilità e la tutela dei diritti fondamentali", in Ars Interpretandi, 2018, 2, pp. 35-56.

${ }^{11}$ ALICI, L. Il fragile e il prezioso. Bioetica in punta dei piedi, Brescia, Morcelliana, 2016, p. 14.

${ }^{12}$ Ibídem.
} 


\section{LA SINGUlarización ATOMÍSTICA DE LOS DERECHOS Y LA NECESIDAD DE RECOMENZAR POR LOS DEBERES}

La edad contemporánea parece escapar de la fragilidad porque la observa con la lente miope del «hombre separado del hombre y de la comunidad, [...] del individuo limitado, limitado sobre sí mismo» ${ }^{13}$, que puede ver la realidad a solo unos centímetros de sus expectativas. Estamos sumidos en una actualidad atomístico-subjetivista, en un contexto siempre más desatado y caracterizado por una concepción existencial en la que prevalece la idea del individuo «auto-productor de sí mismo» ${ }^{14}$, autónomo $\mathrm{y}$ autosuficiente $^{15}$, y de esta forma el otro se deja en segundo plano, en una filigrana insignificante. Como recuerda Byung-Chul Han «el tiempo en que estaba el Otro, se fue. El Otro como misterio, el Otro como seducción, el Otro como Eros, el Otro como deseo, el Otro como infierno, el Otro como dolor desaparece [...]. La expulsión del Otro pone en marcha un tipo diferente de proceso destructivo, es decir lo de autodestrucción» 16 .

La fotografía reciente de Byung-Chul Han enfoca una realidad en la que Pietro Barcellona ya se había detenido extensamente, subrayando la «singularización» ${ }^{17}$, la afirmación del «singular absoluto» ${ }^{18}$, del hombre como «padre único» ${ }^{19}$, «como un niño que nació para decirse a sí mismo que no era hijo de nadie» ${ }^{20}$. Se trata de fotogramas realizados con diferentes dispositivos -analógico el segundo y digital el primero- pero se trata de enfoques que tristemente y nuevamente captan una pérdida del otro, que te hace replegar en ti mismo. Dejarse escapar al otro significa perder la relación positiva con el otro. El encuentro con el otro nos empuja a crecer, a agregar algo. Dejarse escapar al

\footnotetext{
${ }^{13}$ MARX, K. Sulla questione ebraica, in K. MARX, F. ENGELS, Opere, vol. III 1843-1844, Roma, Editori Riuniti, 1976, p. 176.

${ }^{14}$ BARCELLONA, P. L'individuo sociale, Genova, Costa \& Nolan, 1996, p. 7.

${ }^{15}$ Cpd. DUMONT, L. Saggi sull'individualismo, Milano, Adelphi, 1993, p. 88.

${ }^{16}$ HAN, Byung-Chul, L'espulsione dell'altro, Milano, Nottetempo, 2017, p. 7.

${ }^{17}$ BARCELLONA, P. L'individuo sociale, cit., p. 7.

${ }^{18}$ Ibídem.

${ }^{19}$ Ibídem.

20 BARCELlONA, P. L'individuo e la comunità, Roma, Edizioni Lavoro, 2000. Para profundizar el pensamiento de Barcellona, GRECO, T. Modernità, diritto e legame sociale, in Materiali per una storia della cultura giuridica, 2001, n. 2, pp. 517-541.
} 
otro implica también perder la compañía de un «Otro negativo» ${ }^{21}$ que, no teniendo algun trato de nuestra identidad, nos permitirá conocernos aún más y saber quiénes queremos ser, precisamente en virtud de una comparación por diferencia. En ambos casos, en efecto, el otro permite al individuo ver progresivamente sus propios rasgos de identidad, porque frente al otro, en esa reflexión, el hombre percibe a sí mismo por semejanza o por una profunda diferencia.

En sustancia si el yo rechaza la comparación con el otro -tanto con el positivo como con el negativo- se condena a un repliegue sobre sí mismo, que tiene apectos autodestructivos. En efecto, en la «hipertrofia del yo» ${ }^{22}$ de este contexto subjetivista ${ }^{23}$, que pone en el centro «el individuo sin relaciones, sin afectos, sin integración en una comunidad real» ${ }^{24}$, el individuo ${ }^{25}$, el hombre «limitado sobre sí mismo» ${ }^{26}$ parece desear una vida en "second life", en «un "segundo mundo" respecto al real caracterizado por los condicionamientos y los vínculos personales, un mundo completamente atribuible» ${ }^{27}$ a sí mismo, y que «excluye» ${ }^{28}$ la realidad cotidiana, determinada por la comparación con el otro. Sin embargo, como Barcellona siempre recordaba, «una "vida moral" ( formada por reglas y valores) es esencialmente una vida vivida en público, en presencia y en comparación con el otro» ${ }^{29}$.

Ese campo antropológico es el ámbito desde el cual se debe comenzar para un análisis que quiera hablar de deberes, porque es en el marco de la antropología, en el humano que se encarna, que se puede desarrollar la toma de conciencia de la asunción de una obligación, incluso cuando no exista una ley para solicitarla.

Poner énfasis en los deberes, sin olvidar los derechos, significa tratar de recuperar al Otro que ha faltado en el horizonte actual, precisamente a partir de la característica de los deberes que «insisten en los vínculos que unen a los seres humanos, en cambio los

\footnotetext{
${ }^{21} \mathrm{HAN}$, Byung-Chul, L'espulsione dell'altro, cit., pp. 7 ss.

${ }^{22}$ POSSENTI, V. Diritti umani. L'età delle pretese, cit., p. 78.

${ }^{23}$ TAYLOR, Ch. Il disagio della modernità, Roma-Bari, Laterza, 2006, pp. 65-81; AMATO

MANGIAMELI, Agata C. Arte elo tecnica: sfide giuridiche, Padova, Cedam, 2012, p. 141.

${ }^{24}$ POSSENTI, V. Diritti umani. L'età delle pretese, cit., p. 78.

${ }^{25}$ ESPOSITO, R. Communitas. Origine e destino della comunità, Torino, Einaudi, 1998, p. XXIV.

${ }^{26}$ MARX, K. Sulla questione ebraica, cit., p. 176.

${ }^{27}$ Ibídem, p. 26.

${ }^{28}$ BARCELLONA, P. L'individuo sociale, cit., p. 20.

${ }^{29}$ Ibídem, p. 31.
} 
derechos más bien producen su separación» ${ }^{30}$. Es fundamental subrayar este movimiento, abierto o cerrado, que deberes y derechos ponen en marcha: si «los derechos aíslan al individuo, lo delimitan en una "esfera privada", y mejor lo contraponen a otros hombres; los deberes lo obligan a salir de sí mismo, llevándolo inmediatamente hacia el otro» ${ }^{31}$. Por lo tanto el deber presenta una dirección en el camino del hombre, lo induce a salir de sí mismo, a abrir el umbral de una condición individualista y lo empuja necesariamente hacia el otro.

Para llamar la atención sobre la totalidad del hombre, en el que vive el ego pero también tiene residencia el Otro, se debe necesariamente recomenzar desde la asunción de la prioridad de los deberes y poner en el centro la convicción de que «todos estamos vinculados el uno al otro» ${ }^{32}$.

Reinciar de los deberes es, por lo tanto, una prioridad ${ }^{33}$. Si Norberto Bobbio y, por otro lado, Francesco D’Agostino ${ }^{34}$, nos recuerdan que -vista la relación lógica que necesariamente une derechos y deberes- «que se comience por las obligaciones de unos o por los derechos de los otros es, respecto a la sustancia del problema, es absolutamente indiferente» ${ }^{35}$, a través de Greco, en cambio, podemos creer que no sea del todo irrelevante -precisamente por lo que hasta ahora hemos argumentado en el marco antropológico- que se reflexione a partir del lenguaje y de la forma mentis de los derechos, o sea que se arranque por el lenguaje y la orientación planteada por el deber ${ }^{36}$. Recomenzar por el deber puede significar en primer lugar tratar el munus que constituye la esencia de la communitas $^{37}$, que el pensamiento individualista tiende a dejar en segundo plano, "inmunizando" 38 las relaciones sociales y ocultando el valor real del vínculo social.

\footnotetext{
${ }^{30}$ GRECO, T. Prima il dovere. Una critica della filosofia dei diritti, in S. MATTARELLI (a cura di), Il senso della Repubblica. Doveri, Milano, Franco Angeli, 2007, p. 17.

${ }^{31}$ Ibídem

${ }^{32}$ MAZZINI, G. Pensieri sulla democrazia in Europa (orig. 1846), Milano, Feltrinelli, 1997, p. 95.

${ }^{33}$ Cpd. SARTEA, C. Diritti umani. Un'introduzione critica, Torino, Giappichelli, 2018, pp. 23-31.

${ }^{34}$ Cpd. D'AGOSTINO, F. Filosofia del diritto, Torino, Giappichelli, 2000, p. 254.

${ }^{35}$ Cpd. BOBBIO, N. L'età dei diritti, Torino, Einaudi, 1997, p. XIX.

${ }^{36}$ Cpd. GRECO, T. Prima il dovere. Una critica della filosofia dei diritti, cit., p. 23.

${ }^{37}$ Cpd. ESPOSITO, R. Communitas. Origine e destino della comunità, Torino, Einaudi, 1998.

${ }^{38}$ Cpd. ESPOSITO, R., Immunitas. Protezione e negazione della vita, Torino, Einaudi, 2002.
} 


\section{POLIFEMO Y LAS PRETENSIONES FAMÉLICAS DE LA SOCIEDAD DE LOS DERECHOS}

El uso de un lenguaje exclusivamente basado en los derechos ha tenido consecuencias divisivas, conflictividades que han difundido egoísmo e individualismos, y han descuidado «el hecho principal de la naturaleza humana, la sociabilidad» ${ }^{39}$.

Además, como sostiene Aldo Schiavello, «parece que ya esté muy extendida la conciencia de que el lenguaje de los derechos sea el idiolecto a través del cual presentar pretencesiones y reivindicaciones en el ámbito público, si se desea que ambas tengan chances de ser aceptadas» ${ }^{40}$. Una "lengua franca" ${ }^{41}$ que nos ha «tan cautivado [...] que incluso ante sus extrañas consecuencias, nos aferramos a ella y consideramos los problemas que genera como una necesidad de nuevos derechos» ${ }^{42}$, creando en cambio "derechos incorrectos" 43 .

Antonino Spadaro ya lo recordaba, incluso más explícitamente, cuando sostenía la «distorsión de la noción de derecho subjetivo», más bien «su exasperación en un sentido narcisista e hiper-subjetivista - lo que lleva hoy a decir, más o menos explícitamente, que cada "impulso" subjetivo es un derecho, mejor dicho: un derecho fundamental» ${ }^{44}$. Una exasperación en una clave hiper-subjetivista, de la cual deriva que «se consideran derechos fundamentales, o inviolables, situaciones que tal vez ni siquiera son derechos» ${ }^{45}$, olvidando que, «en realidad, [...] los verdaderos derechos fundamentales está relacionados entre ellos» ${ }^{46}$. Luciano Violante habla de una condición en la que se llega a «empujar el campo de los derechos hasta la frontera de los deseos» ${ }^{47}$, una expresión similar a la utilizada, en su crítica hacia la sociedad de los derechos, por

\footnotetext{
${ }^{39}$ MAZZINI, G. Interessi e principii, in Antologia degli scritti politici di Giuseppe Mazzini, a cura di G. Galasso, Bologna, Il Mulino, 1961, p. 82.

${ }^{40}$ SCHIAVELLO, A. "La fine dell'età dei diritti”, in Etica \& Politica, XV, 1, 2013, pp. 120-145.

${ }^{41}$ Ibídem, pp. 143-144.

${ }^{42}$ WOLGAST, E. La grammatica della giustizia, Roma, Editori Riuniti, 1991, p. 33.

${ }^{43}$ Ibídem, pp. 47 ss.

${ }^{44}$ SPADARO, A. Dai "diritti individuali" ai "doveri globali”. La giustizia distributiva internazionale nell'età della globalizzazione, Rubbettino, Soveria Mannelli (CZ) 2005, p. 37.

${ }^{45}$ Ibídem, p. 36.

${ }^{46}$ Ibídem, p. 38.

${ }^{47}$ VIOLANTE, L. Il dovere di avere doveri, Einaudi, Torino, 2014, p. 14.
} 
Umberto Vincenti: «porque los derechos, y su tiempo (el nuestro), han producido (también) fenómenos de degeneración moral y social y, en el imaginario colectivo, los derechos muy frecuentemente se han transformado, e incesantemente siguen transformándose, en simples deseos de tener cosas nuevas y experiencias nuevas, dentro de un horizonte de vida consumista, hedonista -según algunos autores incluso placentero- y ciertamente miserablemente egoísta» ${ }^{48}$.

El deseo tendría que implicar, en su connotación de «falta de algo», la conciencia de la necesidad de pedir, abrirse, sentirse incompleto, frágil y precisar ser completado por otro y otros, y por eso -siendo carente y vacío- ser llenado de significado. Si fuera así, si realmente fuera un deseo, sería (como en el étimo latín) «falta de estrellas», o sea apertura a una mirada trascendente, no solo verticalmente (hacia el Otro) sino también, al menos, horizontalmente (hacia el otro).

Al contrario, relacionada con los derechos, la palabra deseo asume las características de la pretensión a realizar, del impulso individual y narcisista, del sentimiento, de la satisfacción y de la preferencia subjetiva. La dimensión del bien se reduce, en suma, exclusivamente a la felicidad puramente subjetiva ${ }^{49}$.

Estamos sumidos en la edad del «derecho sumo a la felicidad» ${ }^{50}$, en la que se ha perdido la dimensión relacional de los derechos, inscritos en la reciprocidad dictada por los deberes relacionados con ellos, dentro de una perspectiva exclusivamente individual y subjetivista $^{51}$. Por lo tanto, en este horizonte, una «oleada de pretensiones y deseos presentados como derechos [...] ha relegado en segundo plano, si no ha exactamente desconocido, la severa pero indispensable figura del deber» ${ }^{52}$, con la consecuencia de olvidar «que el Ganges de los derechos desciende del Himalaya de los deberes» ${ }^{53}$.

Un modelo basado en pretensiones individuales y en la actitud depredadora es, por lo tanto, similar a el de Polifemo, que se dedica al pastoreo, vive aislado y sin relaciones con la comunidad civil, rodeado solo de cíclopes como él y de ovejas y carneros que

\footnotetext{
${ }^{48}$ VINCENTI, U. Prima il dovere. Una ragionevole critica dei diritti umani, Jovene, Napoli 2011, p. 3.

${ }^{49}$ Cpd. TAYLOR, Ch., Etica e umanità, Vita e Pensiero, Milano 2004, pp. 254-255.

${ }^{50}$ ZAGREBELSKY, G., Diritti per forza, Einaudi, Torino, 2017, pp. 25 ss.

${ }^{51}$ Cpd. ZANETTI, G., Amicizia, felicità, diritto, Roma, Carocci, 1998.

${ }^{52}$ VINCENTI, U. Prima il dovere. Una ragionevole critica dei diritti umani, cit., pp. 4-5.

${ }^{53}$ POSSENTI, V., Diritti umani. L'età delle pretese, cit., p. 112.
} 
cría. El cíclope no respeta sus reglas y no honra a los huéspedes, que devora brutalmente y no respeta a los dioses. En el relato de Homero se destaca su rudeza, su incivismo descrito en un pasaje de la Odisea a través de los actos de canibalismo que el cíclope, hijo de Poseidón, lleva a cabo varias veces.

En la descripción de su primer gesto, repentino y bestial, Homero insiste en varios pasajes sobre los detalles macabros, precisamente para subrayar la crueldad inhumana de la elección del monstruo. No solo es inhospitalidad, es brutalidad inhumana, concebida como un acto animal de satisfacción de su necesidad de llenar el estómago ${ }^{54}$. Polifemo nos muestra la actitud voraz y brutalmente egoísta de quien pretende satisfacer sus prioridades, que sabe cómo encontrar lo que anhela incluso en la oscuridad de su propia cueva. Aquí, en cambio, nos proponemos iluminar una visión diferente de la realidad, «hacer que la dirección de nuestra mirada gire de noventa grados» ${ }^{55}$ y poder responder a la «urgencia de comenzar a pensar (y actuar) "a través de los deberes” y no "a través de los derechos" y [...] reactivar la comunicación y las relaciones entre los individuos» ${ }^{56}$.

En términos concretos, volviendo a las condiciones de vulnerabilidad y a la constitutiva fragilidad humana, de la que hemos iniciado y ejemplificando lo que estamos planteando, centrarnos en los derechos de las personas ciertamente implica definir e implementar proyectos, actividades, servicios que nos permitan apoyar, acompañar, cuidar e capacitar incluso a los que se encuentran en condiciones de vulnerabilidad.

Al mismo tiempo, sin embargo, es necesario preguntarse como cada uno pueda comprender y cuidar la fragilidad de los demás, poniendo a disposición tiempo y capacidades para los que están en condición de necesidad, sin creer que siempre sea alguien a hacerse cargo de ellos, sin pretender siempre «encargar a alguien ${ }^{57}$.

\footnotetext{
${ }^{54}$ Omero, Odissea, trad. it. di G. A. Privitera, Libro IX, vv. 250-295 e 344-414, Mondadori, 1991.

${ }^{55}$ GRECO, T. Prima il dovere. Una critica della filosofia dei diritti, cit., p. 26

${ }^{56}$ Ibídem.

${ }^{57}$ Cpd. WOLGAST, E., La grammatica della giustizia, Roma, Editori Riuniti, 1991.
} 


\section{LA REHABILITACIÓN DEL DEBER COMO RESPONSABILIDAD HACIA EL HOMBRE} FRÁGIL

«La coraza jurídica de la voluntad individual» ${ }^{58}$, que se basa en una libertad concebida «en el aislamiento de cada sujeto de los demás y, en definitiva, de la sociedad misma» 59 y en el marco de «un derecho del individuo limitado, limitado a sí mismo» ${ }^{60}$, resume el lema apropiado «quiero, por lo tanto tengo derechos» ${ }^{61}$.

Todo esto ha caracterizado el "tiempo de los derechos", hasta degenerar en el "tiempo de las pretenciones". ¿Deberíamos entonces abandonar el lenguaje de los derechos? ${ }^{62}$ Aunque sea «muy ambiguo, poco riguroso y usado a menudo retóricamente» ${ }^{63}$, todavía precisamos el lenguaje de los derechos, pero completado con el lenguaje de los deberes. El lenguaje de los derechos tiene «sin duda una gran función práctica, que es la de dar particolar fuerza a las reivindicaciones de los movimientos que exigen para sí y para los demás la satisfacción de nuevas necesidades materiales y morales» ${ }^{64}$. En efecto, el lenguaje de los derechos de matriz individualista y el lenguaje utilizado por los que pertenecen a sectores de la población sometida, vulnerable o maltratada por sus gobiernos, a estratos sociales marginados, a contextos de profunda desigualdad social, son idiomas muy diferentes.

Una cosa, por lo tanto, es afirmar el derecho a la felicidad o a la autodeterminación que quiere el hombre occidental, replegado en sí mismo, insatisfecho y sin relaciones, otra cosa «es denunciar el conjunto de los "sin derechos"» ${ }^{65}$, como recordaba Bobbio ${ }^{66}$.

Para el ser humano humillado «la reivindicación de los derechos significa, en primer lugar y esencialmente, liberación de esta o aquella opresión concreta. Los derechos,

\footnotetext{
${ }^{58}$ ZAGREBELSKY, G., Diritti per forza, cit., p. 21

${ }^{59}$ Ibídem, p. 25

${ }^{60}$ Ibídem.

${ }_{61}^{61}$ Ibídem, p. 23

${ }^{62}$ En relación con la crítica a la teoría y lenguaje de los derechos, cpd. BIN, R. Critica della teoria dei diritti, Milano, Franco Angeli, 2019. Sulla relazione doveri/diritti umani e implicazioni pratiche: PONGIGLIONE, F., I diritti umani nel dibattito etico contemporaneo, Roma, Carocci, 2019, pp. 95-124. ${ }^{63}$ BOBBIO, N. L'età dei diritti, cit., p. XIX.

${ }^{64}$ Ibídem.

${ }^{65}$ Ibídem, p. XX.

${ }^{66}$ Ibídem.
} 
entonces, pertenecen a lo concreto de sus condiciones materiales» ${ }^{67}$. Ante el ser humano indefenso, humillado, desamparado, débil y oprimido, «el fundamento de los derechos reside en los dolores, los abusos, las guerras que han devastado nuestra historia, incluso recientemente» ${ }^{68}$.

La proximidad a la vulnerabilidad, por lo tanto, hace que sea legítimo seguir utilizando el lenguaje de los derechos, porque significa buscar una libertad y una autonomía que no existen, significa trabajar aún hoy en la capacitación de los sometidos ${ }^{69}$.

Al mismo tiempo, sin embargo, como recordaba Franco Cassano, «una sociedad, caracterizada exclusivamente por derechos es una compañía de teléfonos que suenan inútilmente, porque los que deberían responder, siempre tienen algo más importante que hacer» ${ }^{70}$. Sin embargo, visto que «cada persona tiene derechos solo en el marco de las relaciones interpersonales, no puede reclamar derechos dirigiéndose a sí misma» ${ }^{71}$, cada intento de reflexión y reconfiguración del tiempo de las pretensiones individuales requiere un espacio que pueda encontrar la dimensión del vínculo social, de una recuperación «de la relación primera, la que existe entre el yo y el tú» ${ }^{72}$, como apareció lapidariamente en el artículo 2 de la "Declaración de los derechos y deberes del hombre y del ciudadano" (1795): «Todos los deberes del hombre y del ciudadano se deducen de estos dos principios, grabados por la naturaleza en todos los corazones: "No hagas a otros lo que no querrías que te hicieran a ti y haz constantemente a los otros el bien que querrías recibir de ellos"» ${ }^{73}$.

Por lo tanto es el deber cumplido por todos que garantiza el derecho de todos, porque, como ha sido subrayado, «la pluralidad de derechos no puede sostenerse solo como una dinámica mecanicista: los derechos se nutren de la solidariedad y por ende de la

\footnotetext{
${ }^{67}$ ZAGREBELSKY, G., Diritti per forza, cit., p. 24

${ }^{68}$ VINCENTI, U., Prima il dovere. Una ragionevole critica dei diritti umani, cit., p. 49.

${ }^{69}$ En ámbito pedagógico, se vea el aporte fundamental de Paulo Freire, in FREIRE, P., La pedagogia degli oppressi, Torino, EGA, 2002; Id., La pedagogia della speranza, Torino, EGA, 2007. Comentario, cpd. ELLERANI, P.; RIA, D. (a cura di), Paulo Freire pedagogista di comunità: libertà e democrazia in divenire, Lecce, PPE/Università del Salento, 2017.

${ }^{70}$ CASSANO, F., Oltre il nulla. Studio su Giacomo Leopardi, Roma-Bari, Laterza, 2003, p. 54.

${ }^{71}$ ROMANO, B., Il dovere nel diritto. Giustizia, uguaglianza, interpretazione, Giappichelli, Torino 2014, p. 44.

${ }_{73}^{72}$ Ibídem, p. 28.

${ }^{73}$ Cpd. COSEDDU, A., I sentieri del giurista sulle tracce della fraternità. Ordinamenti a confronto, Torino, Giappichelli, 2016, p. 5.
} 
IUS ET SCIENTIA (ISSN 244-8478) 2019, Vol. 5, nº 2, pp. 206-220. LA CEGUERA CIVIL DE POLIFEMO Y LA

"EDAD DE LAS PRETENSIONES". Christian CROCETTA c.crocetta@iusve.it IUSVE Istituto Universitario Salesiano di Venezia Recibido: 17/09/2019. Aceptado: 10/10/2019 DOI: http://doi.org/10.12795/IESTSCIENTIA.2019.102.09

socialidad o de la fraternidad, de lo contrario no sobreviven» ${ }^{74}$.

Necesitamos, por lo tanto, volver al deber, no para reafirmar legalidad y seguridad, como alguien quisiera ${ }^{75}$, sino para resaltar claramente el vínculo esencial entre los derechos y deberes, que pueden reafirmarse juntos, como derechos y deberes fundamentales del hombre ${ }^{76}$. Para poner en evidencia la necesidad de que la coexistencia $^{77}$-deber fundamental, imprescindible e ineludible ${ }^{78}$ - sea una coexistencia solidaria, para un bien no "inmune" sino “común”, para un «vínculo entre hombres» ${ }^{79}$, un vínculo social que convierta el individuo en persona entre otras personas.

\section{REFERENCIAS}

ALICI, L. Il fragile e il prezioso. Bioetica in punta dei piedi, Brescia, Morcelliana, 2016 AMATO MANGIAMELI, Agata C. Arte elo tecnica: sfide giuridiche, Padova, Cedam, 2012

AMATO, S. Coazione, coesistenza, compassione, Torino, Giappichelli, 2002

BARCELLONA, P. L'individuo e la comunità, Roma, Edizioni Lavoro, 2000

BARCELLONA, P. L'individuo sociale, Genova, Costa \& Nolan, 1996

BERNARDINI, M.G., "Il soggetto vulnerabile. Status e prospettive di una categoria (giuridicamente) controversa", in Rivista di filosofia del diritto, Journal of Legal Philosophy, 2017, 2, pp. 365-384

BERTI, G., Manuale di interpretazione costituzionale, Padova, Cedam, 1994

BIN, R. Critica della teoria dei diritti, Milano, Franco Angeli, 2019

BOBBIO, N. L'età dei diritti, Torino, Einaudi, 1997

CASSANO, F., Oltre il nulla. Studio su Giacomo Leopardi, Roma-Bari, Laterza, 2003

\footnotetext{
${ }^{74}$ BERTI, G., Manuale di interpretazione costituzionale, Padova, Cedam, 1994, p. 506.

${ }^{75}$ Cpd. GRECO, T. Prima il dovere. Una critica della filosofia dei diritti, cit., p. 17.

${ }^{76}$ D'AGOSTINO, F., Filosofia del diritto, cit., p. 254.

${ }^{77}$ Cpd. AMATO, S. Coazione, coesistenza, compassione, Torino, Giappichelli, 2002.

${ }^{78}$ D’AGOSTINO, F., Filosofia del diritto, cit., p. 259.

${ }^{79}$ MARX, K., Sulla questione ebraica, cit., p. 176.
} 
IUS ET SCIENTIA (ISSN 244-8478) 2019, Vol. 5, nº 2, pp. 206-220. LA CEGUERA CIVIL DE POLIFEMO Y LA

"EDAD DE LAS PRETENSIONES". Christian CROCETTA c.crocetta@iusve.it IUSVE Istituto Universitario Salesiano di Venezia Recibido: 17/09/2019. Aceptado: 10/10/2019 DOI: http://doi.org/10.12795/IESTSCIENTIA.2019.i02.09

CHENAL, R., "La definizione della nozione di vulnerabilità e la tutela dei diritti fondamentali", in Ars Interpretandi, 2018, 2, pp. 35-56

COSEDDU, A., I sentieri del giurista sulle tracce della fraternità. Ordinamenti a confronto, Torino, Giappichelli, 2016

D’AGOSTINO, F. Filosofia del diritto, Torino, Giappichelli, 2000

DUMONT, L. Saggi sull'individualismo, Milano, Adelphi, 1993

ELLERANI, P.; RIA, D. (a cura di), Paulo Freire pedagogista di comunità: libertà e democrazia in divenire, Lecce, PPE/Università del Salento, 2017.

ESPOSITO, R. Communitas. Origine e destino della comunità, Torino, Einaudi, 1998

ESPOSITO, R., Immunitas. Protezione e negazione della vita, Torino, Einaudi, 2002.

FODDAI, M.A., Sulle tracce della responsabilità. Idee e norme dell'agire responsabile, Torino, Giappichelli, 2005

FREIRE, P., La pedagogia degli oppressi, Torino, EGA, 2002

FREIRE, P., La pedagogia della speranza, Torino, EGA, 2007

GIOLO, O; PASTORE, B., Vulnerabilità. Analisi multidisciplinare di un concetto, Roma, Carocci, 2018

GRECO, T. Modernità, diritto e legame sociale, in Materiali per una storia della cultura giuridica, 2001, n. 2, pp. 517-541

GRECO, T., Prima il dovere. Una critica della filosofia dei diritti, in S. Mattarelli (a cura di), Il senso della Repubblica. Doveri, Milano, Franco Angeli, 2007, pp. 15-30.

GROSSI, P., Prima lezione di diritto, Roma-Bari, Laterza, 2007

GUASTINI, R., "Dovere giuridico", in Enc. Giur., 1990, XXI, 4

GUASTINI, R., "Obbligo”, in Enc. Giur., 1990, XXI

HAN, Byung-Chul, L'espulsione dell'altro, Milano, Nottetempo, 2017

MARX, K. Sulla questione ebraica, in K. MARX, F. ENGELS, Opere, vol. III 18431844, Roma, Editori Riuniti, 1976.

MAZZINI, G. Interessi e principii, in Antologia degli scritti politici di Giuseppe Mazzini, a cura di G. Galasso, Bologna, Il Mulino, 1961.

MAZZINI, G. Pensieri sulla democrazia in Europa (orig. 1846), Milano, Feltrinelli, 1997 
IUS ET SCIENTIA (ISSN 244-8478) 2019, Vol. 5, nº 2, pp. 206-220. LA CEGUERA CIVIL DE POLIFEMO Y LA

"EDAD DE LAS PRETENSIONES". Christian CROCETTA c.crocetta@iusve.it IUSVE Istituto Universitario Salesiano di Venezia Recibido: 17/09/2019. Aceptado: 10/10/2019 DOI: http://doi.org/10.12795/IESTSCIENTIA.2019.i02.09

Omero, Odissea, trad. it. di G. A. Privitera, Libro IX, vv. 250-295 e 344-414, Mondadori, 1991.

PECES BARBA MARTINEZ, G., "Diritti e doveri fondamentali", in Dig. Disc. pubbl., 1990, V, 139

PONGIGLIONE, F., I diritti umani nel dibattito etico contemporaneo, Roma, Carocci, 2019

POSSENTI V., Diritti umani. L'età delle pretese, Soveria Mannelli (CZ), Rubbettino, 2017.

ROMANO, B., Il dovere nel diritto. Giustizia, uguaglianza, interpretazione, Giappichelli, Torino, 2014

SARTEA, C. Diritti umani. Un 'introduzione critica, Torino, Giappichelli, 2018

SCHIAVELLO, A. "La fine dell'età dei diritti", in Etica \& Politica, XV, 1, 2013, pp. $120-145$

SPADARO, A. Dai "diritti individuali" ai "doveri globali". La giustizia distributiva internazionale nell'età della globalizzazione, Rubbettino, Soveria Mannelli (CZ) 2005

TARLI BARBIERI, G., "Doveri inderogabili", in Dizionario di diritto pubblico, III, Milano, 2006, pp. 2066 ss.

TAYLOR, Ch. Il disagio della modernità, Roma-Bari, Laterza, 2006

TAYLOR, Ch., Etica e umanità, Vita e Pensiero, Milano 2004

VERGANI, M., Responsabilità. Rispondere di sé, rispondere all'altro, Milano, Raffaello Cortina, 2015

VINCENTI, U. Prima il dovere. Una ragionevole critica dei diritti umani, Jovene, Napoli 2011

VIOLANTE, L. Il dovere di avere doveri, Einaudi, Torino, 2014

WEIL, S., La prima radice. Preludio a una dichiarazione dei doveri dell'uomo, Milano, Edizioni di Comunità, 2017

WOLGAST, E. La grammatica della giustizia, Roma, Editori Riuniti, 1991

ZAGREBELSKY, G., Diritti per forza, Einaudi, Torino, 2017

ZANETTI, G., Amicizia, felicità, diritto, Roma, Carocci, 1998

ZANETTI, G., Filosofia della vulnerabilità, Carocci, Roma, 2019 
IUS ET SCIENTIA (ISSN 244-8478) 2019, Vol. 5, nº 2, pp. 206-220. LA CEGUERA CIVIL DE POLIFEMO Y LA

"EDAD DE LAS PRETENSIONES". Christian CROCETTA c.crocetta@iusve.it IUSVE Istituto Universitario Salesiano di Venezia Recibido: 17/09/2019. Aceptado: 10/10/2019 DOI: http://doi.org/10.12795/IESTSCIENTIA.2019.i02.09

ZATTI P., "Parole fra noi così diverse». Per un'ecologia del rapporto terapeutico", in Nuova Giur. Civ. Comm., 3, 2012, pp. 143-150.

$* * *$

\section{Prof. Christian Crocetta}

IUSVE Istituto Universitario Salesiano di Venezia

Dipartimento di Pedagogia

Via dei Salesiani 15, 30174 Venezia - Mestre (Italia)

mail: 